http://jmscr.igmpublication.org/home/ ISSN (e)-2347-176x ISSN (p) 2455-0450

crossref DOI: https://dx.doi.org/10.18535/jmscr/v8i11.73

Journal Of Medical Science And Clinical Research

IGM Publication

An Official Publication of IGM Publication

\title{
Study of Serum Calcium as a Prognostic Marker in Acute Ischemic Stroke
}

\author{
Authors \\ Dr Amudalapalli L A Alekhya ${ }^{1}$, Dr K. Indira Devi M.D. ${ }^{2}$, Dr T. Manasa ${ }^{3}$ \\ ${ }^{1}$ Post graduate, Department of General Medicine \\ ${ }^{2}$ Professor, Department of General Medicine \\ ${ }^{3}$ Post graduate, Department of General Medicine \\ King George Hospital
}

\begin{abstract}
Background: The objective of this study is to assess the role of serum calcium and its significance as a prognostic marker in acute ischemic stroke.

Materials and Methods: This is a cross-sectional study done over a period of 8 months in the department of General Medicine, King George Hospital, Visakhapatnam from January 2020 to August 2020. A total of 75 patients admitted in the ward with CT confirmed ischemic stroke were included in the study

Results: Low blood calcium levels occurred in patients with age $>60$ years consistently compared to patients with age $<60$ years among ischemic stroke patients. Low blood calcium levels occurred in female patients consistently compared to male patients among ischemic stroke patients. Low blood calcium levels occurred in diabetes mellitus patients consistently compared to non-diabetes mellitus patients among ischemic stroke patients. Low blood calcium levels occurred in patients with NIHSS score (Severe Stroke category (21-41)) significantly $(p<0.05)$ compared to patients with NIHSS score (Minor Stroke category (1-4)) among ischemic stroke patients. Low blood calcium levels occurred in patients with poor outcome status as per MRS significantly $(p<0.05)$ compared to patients with good outcome status as per MRS among ischemic stroke patients.

Conclusion: We conclude that serum calcium levels have strong correlation with severity and functional outcome in acute ischemic stroke patients and hence it can be taken as a marker prognostic significance in these patients.

Keywords: Serum calcium, Acute ischemic stroke, Prognostic factor.
\end{abstract}

\section{Introduction}

Cell calcium metabolism during and immediately after a transient period of ischemia influences the cascade of events that leads to subsequent neuronal injury.

$\mathrm{Ca} 2+$ has also been studied with regard to its relationship with stroke risk factors and stroke incidence. High dietary intake of $\mathrm{Ca} 2+$ has been associated with reduced risk of stroke. The present study has been done with the aim of determining the role of serum calcium in assessing the severity and prognosis of acute ischemic stroke patients.

\section{Aims and Objectives}

1. To determine serum calcium as an prognostic marker in Acute ischemic stroke. 
2. To correlate serum calcium level with severity of stroke using NIHSS stroke score and assessing the prognosis.

\section{Methodology}

Study Design: A cross sectional study

Study Duration: 8 months (Jan 2020 - Aug 2020)

Study Setting: The study was conducted in the King George Hospital, Visakhapatnam. The samples were selected among the inpatients who were admitted under the department of general medicine.

\section{Inclusion Criteria}

1) Age group from 18 to 80 years.

2) Acute ischemic stroke diagnosed by clinical examination and CT brain plain.

3) Patients who are willing to participate in the study -consent form signed by patient or attender.

\section{Exclusion Criteria}

1) Patients with age more than 80 years were excluded.

2) Patients with malignancy, sepsis, trauma, recent surgery

3) Patients with prior history of transient ischemic attacks or reversible ischemic neurological deficit.

4) Patients with features of hemorrhage confirmed by CT.

\section{Study Setting}

75 patients who were admitted in the ward as inpatient under the department of general medicine with CT confirmed ischemic stroke, in King George Hospital, Visakhapatnam.

\section{Statistical Analysis}

Multivariate analysis, Pearson correlation analysis and chi -square test is applied for significance .p value $<0.05$ is considered as significant.

\section{Results}

Out of 75 participants, $45(60 \%)$ patients presented with ischemic stroke had low serum calcium while $30(40 \%)$ participants had normal level of serum calcium.
Among 45 participants with decreased serum calcium majority were males with $53.3 \%$ (24) and females were less comparatively with $46.6 \%$

Out of the patients with normal serum calcium majority $83.3 \%$ (25) belong to male gender while rest $16.6 \%$ (5) belong to female gender.

Among 45 patients who had low serum calcium majority, $97.8 \%$ (44) had poor outcome of the disease while $80 \%$ (24) with normal calcium level had comparatively poor outcome. Only $2.22 \%$ (1) patient with low blood calcium had good prognosis whereas $20 \%$ (6) with normal calcium had good prognosis, which is comparatively higher.

When analysing NIHSS score status between the study groups, a trend of higher NIHSS score presentation (Severe Stroke category (21-41)) was observed in low blood calcium group (48.89\%) compared to normal blood calcium group $(0.00 \%)$. The increased difference in percentage of NIHSS score (Severe Stroke category (21- 41)) presentation between low calcium group and normal calcium group (48.89 percentage points, 95\% higher) was found to be statistically significant $(\mathrm{p}<0.05)$.

\begin{tabular}{|c|c|c|c|c|}
\hline $\begin{array}{l}\text { National Institute of } \\
\text { Health Stroke Scale }\end{array}$ & $\begin{array}{l}\text { Low Blood } \\
\text { Calcium }\end{array}$ & $\%$ & $\begin{array}{l}\text { Normal Blood } \\
\text { Calcium }\end{array}$ & $\%$ \\
\hline Minor Stroke (1-4) & 1 & 2.22 & 13 & $\begin{array}{l}43.3 \\
3\end{array}$ \\
\hline Moderate Stroke (5-15) & 8 & $\begin{array}{l}17.7 \\
8\end{array}$ & 11 & $\begin{array}{l}36.6 \\
7\end{array}$ \\
\hline $\begin{array}{l}\text { Moderate to severe stroke } \\
(16-20)\end{array}$ & 14 & $\begin{array}{l}31.1 \\
1\end{array}$ & 6 & $\begin{array}{l}20.0 \\
0\end{array}$ \\
\hline Severe Stroke (21-41) & 22 & $\begin{array}{l}48.8 \\
9\end{array}$ & 0 & 0.00 \\
\hline Total & 45 & $\begin{array}{l}100 . \\
00\end{array}$ & 30 & $\begin{array}{l}100 . \\
00\end{array}$ \\
\hline
\end{tabular}

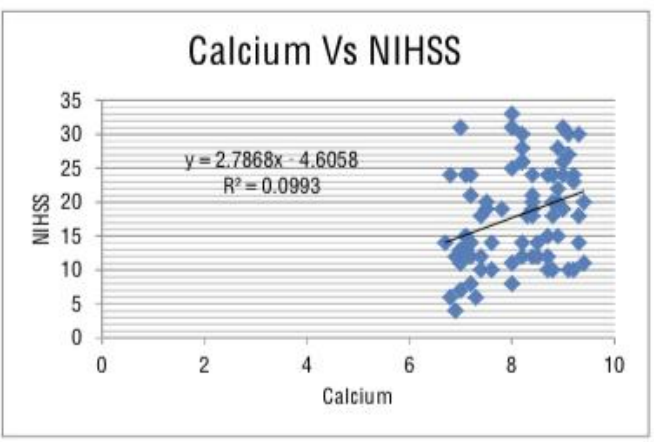




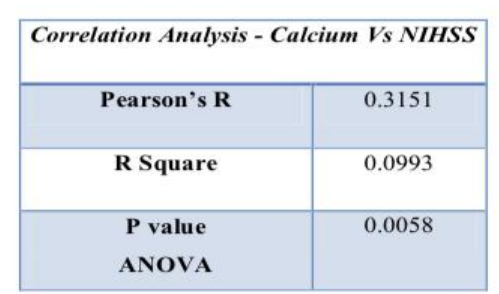

The relationship between blood calcium levels and NIHSS scores, a positive correlation was observed with a Pearson's coefficient of 0.32 . It was statistically significant with a p-value of 0.0058 according to ANOVA test.

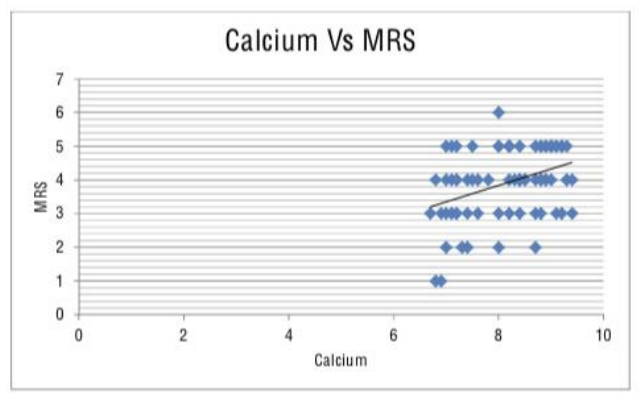

\begin{tabular}{|c|c|}
\hline \multicolumn{2}{|c|}{ Correlation Analysis - Calcium Vs MRS } \\
\hline Pearson's R & 0.3781 \\
\hline R Square & 0.1429 \\
\hline P value & 0.0008 \\
ANOVA & \\
\hline
\end{tabular}

The relationship between blood calcium levels and MRS scores, a positive correlation was observed with a Pearson's coefficient of 0.38 . It was statistically significant with a p-value of 0.0008 according to ANOVA test

\section{Discussion}

In our study, majority of the participants (60\%) had low levels of serum calcium than participants with normal calcium range. The normal corrected calcium value taken, range from 8.6to 10.2, where the level less than 8.6 is considered to be low and more than 10.2 is considered as high calcium level. With this corrected calcium range as base the distribution of participants were done. Each group has been compared with the demographic factors such as age and gender along with the personal habits such as alcohol and smoking and also with the diabetic and hypertension status of the participants. Finally the calcium levels are compared with the NIHSS and the MRS. From all these it is found that majority of the study population were in the age group 61 to 70 years with $55.56 \%$ and the male gender was high among the study participants with $53.2 \%$. Most of the participants with low calcium level were non- alcoholic whereas equal distribution was found among the patients with normal calcium values. Regarding smoking habit more number of study subjects belongs to low calcium group were non-smokers. $53.3 \%$ were diabetic among the low calcium group and $26.75 \%$ had positive history of diabetes mellitus among the normal serum calcium group. Most of the participants in the group of decreased calcium were found to be hypertensive compared to the participants in the category of normal blood calcium.

Significant association was noted between the age distribution and the level of calcium with p-value $<0.001$, gender with p-value 0.007 , diabetes mellitus with p-value 0.022 . No significant association between smoking, alcohol and the status of the blood pressure. Significant association was seen when NIHSS is compared with the calcium and the significance also noted when calcium is compared with MRS, with pvalue $<0.0001$ and 0.0102 respectively. ANOVA test was done which also elicited significant association between the calcium and NIHSS.

Muhammed Ishfaq, Fahim Ullah, et,.al.. Conducted a study titled "correlation of serum calcium with severity of acute ischemic stroke" inferred that lower serum calcium is associated with more sever clinical finding at the onset of stroke and proved the significance with the help of Bivariate analysis and Pearson's correlation coefficient was significant (p-value 0.005).

\section{Conclusion}

Ischemic stroke patients with low blood calcium levels had bad prognosis. Female Ischemic stroke patients aged $>60$ years with low blood calcium levels and comorbid conditions like diabetes mellitus had grave prognosis. 


\section{Limitation}

The study is done in a limited number of patients. Results may vary when done in a large number of subjects.

\section{References}

1. Gupta A, Dubey U, Kumar A, Singh S. Correlation of serum calcium levels with severity and functional outcome in acute ischemic stroke patients. Int J Res Med Sci 2015;3:3698-702

2. Chung, J.W., Ryu, W.S., Kim, B.J., Yoon, B.W. Elevated Calcium after Acute Ischhemic Stroke: Associated with a Poor Short-Term Outcom and LongTerm Mortality. Journal of Stroke. 2015.17(1): 54-59.

3. Powers WJ, Derdeyn CP, Biller J, Coffey CS, Hoh BL, Jauch EC, et al. 2015 AHA/ASA Focused Update of the 2013 Guidelines for the Early Management of Patients With Acute Ischemic Stroke Regarding Endovascular Treatment: A Guideline for Healthcare Professionals From the American Heart Association/ American Stroke Association. Stroke.2015 Jun 29.

4. Arboix A, Alio J. Acute cardioembolic cerebral infarction: answers to clinical questions. Curr Cardiol Rev. 2012 Feb. 8(1):54-67.

5. Borah M, Dhar S, Gogoi DM, Ruram AA. Associationof serum calcium levels with infarct size in acute ischemic stroke: Observations from Northeast India. J Neurosci Rural Pract 2016;7:S41-5.

6. Clarke CRA. Neurological diseases. In: Kumar P, Clark M, eds. Clinical medicine. 7th ed. New Delhi: Saunders Elsevier, 2009; pp 1126.

7. Correlation of serum calcium with severity of acute ischaemic stroke, Muhammad Ishfaq Vol. 67, No. 1, January 2017,p-2023. 